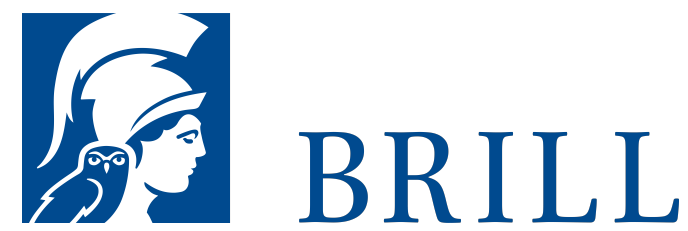

\title{
Breaking Down BREAKING BAD
}

Dramaturgie und Ästhetik einer Fernsehserie. 2. Auflage

Authors: Christine Lang and Christoph Dreher

Mit BREAKING BAD ist dem Creator und Showrunner Vince Gilligan eine bahnbrechende Innovation gelungen: mit der haarsträubenden Story von einem unscheinbaren Chemielehrer, der von der Not getrieben zum Drogenkoch und zur lebenden Gangsterlegende mutiert, werden die Möglichkeiten der Langform-Erzählung zur Schilderung einer extremen Entwicklung einer Figur maximal genutzt.

Das Buch befasst sich in unterschiedlichen Essays mit den dramaturgischen und erzählerischen Eigenschaften der Fernsehserie, die neue Maßstäbe auf dem Gebiet des Scriptwriting aufstellt. Implizite Dramaturgie, popkulturelle Referenzialität, extreme Figurenentwicklung und metaphorisches Erzählen - Stichworte und Themen, die in diesen Analysen eine zentrale Rolle spielen. Der Bericht von einem Besuch am Set von BREAKING BAD in Albuquerque gibt Einblicke in Arbeitsweisen und Haltungen des Creators und seines Teams.

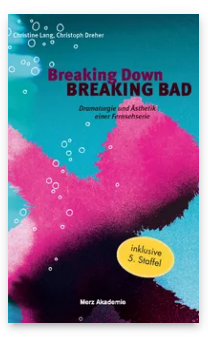

Pages: 178 Seiten, 30 farb. Abb.

Language:

German

Subjects:

General, Media

\section{Studies}

Publisher: Brill |

Fink

Series:

Merz Akademie

Paperback

Publication date:

17 Nov 2014

ISBN: 978-3-

7705-5813-1

List price

USD \$40.00 
For more information see brill.com

Order information: Order online at brill.com +44330 333 0049 | customerservices@brill.com Submission information: brill.com/authors

Titles published by Brill | Fink, Brill | mentis or Brill | Schöningh: +49(o)715413279216| brill@brocom.de 